ORNL/TM-2005/10

CONTROL OF URANIA CRYSTALLITE SIZE BY HMTA-UREA REACTIONS IN THE INTERNAL GELATION PROCESS FOR PREPARING (U, Pu)O $\mathrm{O}_{2}$ FUEL KERNELS

J. L. Collins

M. H. Lloyd

S. E. Shell 


\section{DOCUMENT AVAILABILITY}

Reports produced after January 1, 1996, are generally available free via the U.S. Department of Energy (DOE) Information Bridge:

Web site: http://www.osti.gov/bridge

Reports produced before January 1, 1996, may be purchased by members of the public from the following source:

National Technical Information Service

5285 Port Royal Road

Springfield, VA 22161

Telephone: 703-605-6000 (1-800-553-6847)

TDD: 703-487-4639

Fax: 703-605-6900

E-mail: info@ntis.fedworld.gov

Web site: http://www.ntis.gov/support/ordernowabout.htm

Reports are available to DOE employees, DOE contractors, Energy Technology Data Exchange (ETDE) representatives, and International Nuclear Information System (INIS) representatives from the following source:

Office of Scientific and Technical Information

P.O. Box 62

Oak Ridge, TN 37831

Telephone: 865-576-8401

Fax: 865-576-5728

E-mail: reports@adonis.osti.gov

Web site: http://www.osti.gov/contact.html

This report was prepared as an account of work sponsored by an agency of the United States Government. Neither the United States government nor any agency thereof, nor any of their employees, makes any warranty, express or implied, or assumes any legal liability or responsibility for the accuracy, completeness, or usefulness of any information, apparatus, product, or process disclosed, or represents that its use would not infringe privately owned rights. Reference herein to any specific commercial product, process, or service by trade name, trademark, manufacturer, or otherwise, does not necessarily constitute or imply its endorsement, recommendation, or favoring by the United States Government or any agency thereof. The views and opinions of authors expressed herein do not necessarily state or reflect those of the United States Government or any agency thereof. 
Nuclear Science and Technology Division

\title{
CONTROL OF URANIA CRYSTALLITE SIZE BY HMTA-UREA REACTIONS IN THE INTERNAL GELATION PROCESS FOR PREPARING (U, Pu) $\mathrm{O}_{2}$ FUEL KERNELS
}

\author{
J. L. Collins \\ M. H. Lloyd* \\ S. E. Shell
}

Date Published: April 2005

\author{
Prepared by \\ OAK RIDGE NATIONAL LABORATORY \\ P.O. Box 2008 \\ Oak Ridge, Tennessee 37831-6285 \\ managed by \\ UT-BATTELLE, LLC \\ for the \\ U.S. DEPARTMENT OF ENERGY \\ under contract DE-AC05-00OR22725
}

*Formerly members of the Chemical Technology Division, ORNL. 



\section{CONTENTS}

Page

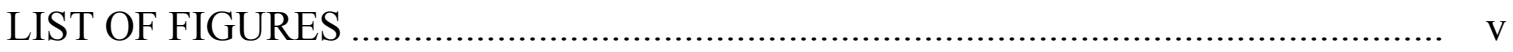

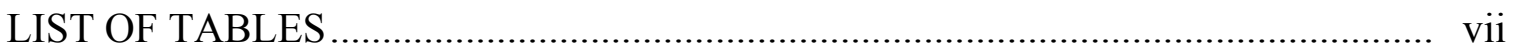

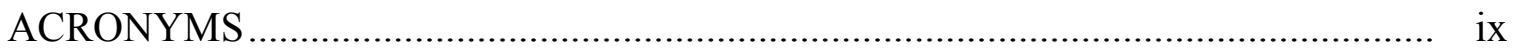

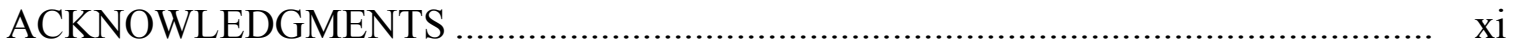

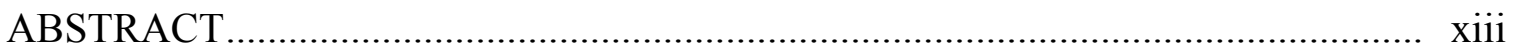

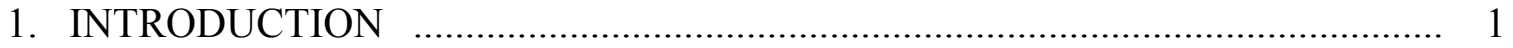

2. METHOD OF BROTH PREPARATION ……………...................................... 2

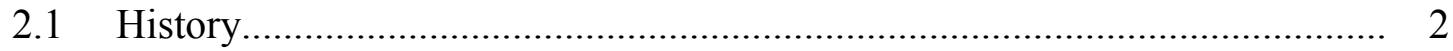

2.2 Preparation of Heated HMTA-Urea Stock Solutions...................................... 3

3. CHARACTERIZATION OF HEATED HMTA-UREA SOLUTIONS ................... 4

3.1 Determination of HMTA Molarity by Potentiometric Titration....................... 6

3.2 Quantifying Ammonia Released from Heated Solutions of

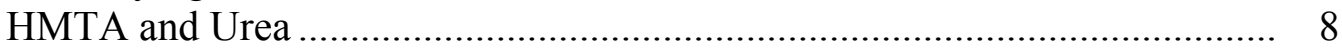

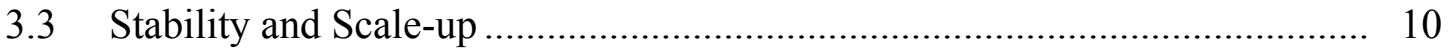

3.4 Role of Urea in Heated HMTA-Urea Solutions........................................... 14

3.5 Effect of Urea/(U + Pu) Mole Ratio on Tap Density and Product Quality..... 15

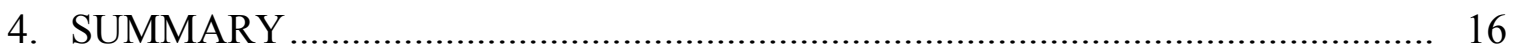

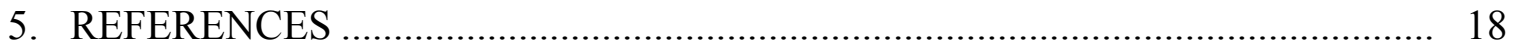





\section{LIST OF FIGURES}

Figure

Page

1 Schematic of apparatus used to boil 3.2 $M$ HMTA-3.2 $M$ urea solutions............ 5

2 Titration profiles for three HMTA-urea solutions: A, boiled for $15 \mathrm{~min}$;

$\mathrm{B}$, boiled for $60 \mathrm{~min}$; and $\mathrm{C}$, not boiled.

3 Titration profiles for three HMTA-urea solutions: A, boiled for $60 \mathrm{~min}$;

$\mathrm{B}$, boiled for $75 \mathrm{~min}$; and $\mathrm{C}$, boiled for $191 \mathrm{~min}$.

$4 \quad$ Moles of $\mathrm{NH}_{3}$ released from 0.5 - and 2-L solutions of

3.2 $M$ HMTA-3.2 $M$ urea as a function of boiling time

5 Effect of HMTA-urea boiling time on tap density.....

6 Effect of changing $\mathrm{HMTA} /(\mathrm{U}+\mathrm{Pu})$ mole ratio on gelation time, tap density, and surface quality for unheated and 60-min boiled

3.2 $M$ HMTA-3.2 $M$ urea solutions....

7 Effect of varying the $\mathrm{NO}_{3}{ }^{-} /(\mathrm{U}+\mathrm{Pu})$ mole ratio on gelation time, tap density, and surface quality for unheated and 60 -min boiled

3.2 $M$ HMTA-3.2 $M$ urea solutions.... 



\section{LIST OF TABLES}

$\begin{array}{lll}\text { Table } & \text { Page }\end{array}$

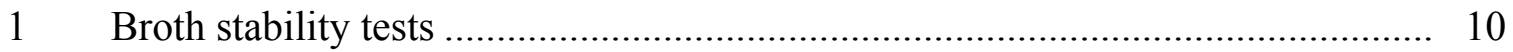

2 Effect of urea concentration in the broth on tap density .................................. 15 



\section{ACRONYMS}

$\begin{array}{ll}\text { ADMN } & \text { acid-deficient metal nitrate } \\ \text { AGR } & \text { advanced gas-cooled reactor } \\ \text { DIPRES } & \text { Direct Press Spheroidized (process) } \\ \text { DOE } & \text { U.S. Department of Energy } \\ \text { HMTA } & \text { hexamethylenetetramine } \\ \text { ORNL } & \text { Oak Ridge National Laboratory } \\ \text { TCE } & \text { trichloroethylene } \\ \text { TRISO } & \text { triisotropic }\end{array}$





\section{ACKNOWLEDGMENTS}

The authors appreciate Dave Hill, Jim Rushton, and Ben Lewis, for their managerial support; G. D. Del Cul and R. D. Hunt, for their helpful technical reviews; Brenda Johnson, for preparation of the document; and Marsha Savage, for editing. 



\begin{abstract}
In the development of $(\mathrm{U}, \mathrm{Pu}) \mathrm{O}_{2}$ kernels by the internal gelation process for the Direct Press Spheroidized process at Oak Ridge National Laboratory, a novel crystal growth step was discovered that made it possible to prepare calcined porous kernels that could be used as direct-press feed for Fast Breeder Reactor pellet fabrication. Highquality pellets were prepared that were near theoretical density and that (upon examination) revealed no evidence of sphere remnants. The controlled crystal growth step involved using hexamethylenetetramine (HMTA)-urea stock solutions that were boiled for $60 \mathrm{~min}$ or less. Before this discovery, all the other crystal growth steps (when utilized) could reduce the tap density to only $\sim 1.3 \mathrm{~g} / \mathrm{cm}^{3}$, which was not sufficiently low for use in ideal pellet pressing. The use of the boiled HMTA-urea solution allowed the tap density to be lowered to $0.93 \mathrm{~g} / \mathrm{cm}^{3}$, with the ideal density being about $1.0 \mathrm{~g} / \mathrm{cm}^{3}$. This report describes the development of this technology and its scaleup.
\end{abstract}





\section{INTRODUCTION}

The internal gelation process used at Oak Ridge National Laboratory (ORNL) was originally developed at the KEMA laboratory located in the Netherlands. ${ }^{1}$ During the late 1970s and throughout the 1980s, researchers at ORNL studied and developed the internal gelation process for making $\mathrm{UO}_{2},(\mathrm{U}, \mathrm{Pu}) \mathrm{O}_{2}, \mathrm{ThO}_{2}$, and $\left(\mathrm{UO}_{2}+\mathrm{UC}_{2}\right)$ microspherical fuels. ${ }^{2-16}$ More recently, as a task of the Advanced Gas-Cooled Reactor (AGR) Program at ORNL, about $2 \mathrm{~kg}$ of $\mathrm{UO}_{2}$ kernels with diameters of $500 \pm 20 \mu \mathrm{m}$ and $3.5 \mathrm{~kg}$ of $\mathrm{UO}_{2}$ kernels with diameters of $350 \pm 10 \mu \mathrm{m}$ were prepared for use in the triisotropic (TRISO) coating development. ${ }^{17}$ The internal gelation process used is one of the sol-gel processes developed for the preparation of microspheres of nuclear fuel in which chilled clear broth droplets containing acid-deficient metal nitrate (ADMN), hexamethylenetetramine (HMTA), and urea are heated, causing homogenous gelation and solidification of the droplets. After washing treatments, these droplets can then be dried, calcined, and sintered to produce ceramic kernels of the required density. In the development of the internal gelation process, a number of process parameters have been determined that serve as useful tools in controlling the quality of the kernels

produced. ${ }^{2,8,10-12,17}$ Understanding the crystal morphology of uranium is essential for the preparation of $\mathrm{UO}_{2},(\mathrm{U}, \mathrm{Pu}) \mathrm{O}_{2}$, and $\left(\mathrm{UO}_{2}+\mathrm{UC}_{2}\right)$ kernels. The crystal morphology of uranium and the concomitant microsphere properties are significantly affected by (1) the $\mathrm{HMTA} / \mathrm{U}$ mole ratio, (2) the $\mathrm{NO}_{3}{ }^{-} / \mathrm{U}$ mole ratio, (3) the concentration of uranium in the broth, and (4) the gel-forming temperature. After gel-sphere formation, it was also found that hot-oil aging and air-drying had important impacts on crystallite growth. All of these process parameters were extensively studied, especially in the development of $(\mathrm{U}, \mathrm{Pu}) \mathrm{O}_{2}$

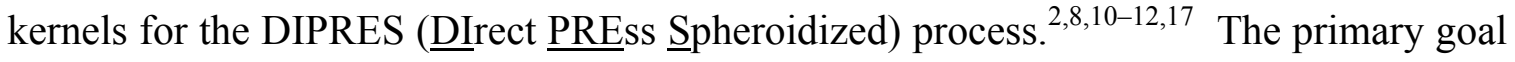
of the DIPRES process was to prepare highly porous, low-density calcined microspheres that could be used as direct-press feed for Fast Breeder Reactor pellet fabrication. Ideal pellets were ones with near-theoretical density $\left(11.08 \mathrm{~g} / \mathrm{cm}^{3}\right)$ whose matrices showed little or no evidence of sphere remnants upon examination. In this work it was discovered that the uranium crystallinity controlled the tap density or porosity of the microspheres. By optimizing the above-mentioned crystal growth parameters, it was 
possible to decrease the tap density of microspheres from 2.7 to $1.27 \mathrm{~g} / \mathrm{cm}^{3}$. However, this density was not low enough for use in ideal pellet pressing. Fortuitously, an additional crystal growth step was discovered. It was found that boiling HMTA-urea stock solutions for certain periods of time could lower the tap density of the microspheres to $0.93 \mathrm{~g} / \mathrm{cm}^{3}$. Furthermore, the boiling process could be controlled so that stock solutions could be prepared and used to obtain any targeted tap density between 1.27 and $0.93 \mathrm{~g} / \mathrm{cm}^{3}$. Microspheres with tap densities $<1.0 \mathrm{~g} / \mathrm{cm}^{3}$ proved to be ideal for the DIPRES process.

It is the purpose of this report to describe the development and use of boiled HMTA-urea stock solutions in the internal gelation process as a viable crystal growth step used to prepare porous microspheres for the DIPRES process. Most of the testing was directed at the preparation of $(\mathrm{U}, \mathrm{Pu}) \mathrm{O}_{2}$ kernels.

\section{METHOD OF BROTH PREPARATION}

\subsection{History}

The key to the internal gelation process is the ability to prepare clear droplets of broth that contain high concentrations of metallic salts, HMTA, and urea at low temperatures $\left(0\right.$ to $\left.5^{\circ} \mathrm{C}\right)$. Droplets with the highest metallic concentration are ones in which the metallic salt has been partially hydrolyzed or made acid deficient. When these droplets of idealized formulation are introduced into a heated immiscible organic liquid such as silicone oil or trichloroethylene (TCE), the metallic salts within the droplets begin to homogenously gel and become opaque within a few seconds. ${ }^{12,17}$ After solidification, aging, washing, and drying, the microspheres are calcined and sintered to ceramic kernels. The primary methods used for clear broth preparations are as follows:

1. Solid HMTA is added to a solution of ADMN and urea at $0^{\circ} \mathrm{C}$ and mixed.

2. An aqueous solution of HMTA $\left(\right.$ at $0^{\circ} \mathrm{C}$ ) is added to a solution of ADMN containing urea $\left(\right.$ at $\left.0^{\circ} \mathrm{C}\right)$ and mixed.

3. An aqueous solution of HMTA and urea $\left(\right.$ at $\left.0^{\circ} \mathrm{C}\right)$ is added to a solution of ADMN $\left(\right.$ at $0^{\circ} \mathrm{C}$ ) and mixed. 
In methods (1) and (2), urea is first added to the $\mathrm{ADMN}$ and heated at $50^{\circ} \mathrm{C}$ with stirring for about $24 \mathrm{~h}$. This step destroys any nitrite that might be present in the ADMN as shown in the following equation. Stirring was important for degassing the solution.

$$
\left(\mathrm{NH}_{2}\right)_{2} \mathrm{CO}+2 \mathrm{HNO}_{2} \rightarrow \mathrm{CO}_{2} \uparrow+2 \mathrm{~N}_{2} \uparrow+3 \mathrm{H}_{2} \mathrm{O}
$$

During the early development of the internal gelation process, it was believed that any nitrite in the broth would cause gassing during the forming and aging steps, which could cause the spheres to crack. Carbon dioxide $\left(\mathrm{CO}_{2}\right)$ and nitrogen $\left(\mathrm{N}_{2}\right)$ gases are generated by the reaction of the urea with nitrite under acid conditions. In method (1), broths can be prepared with higher concentrations of metal. It was later discovered that method (3) worked as well as the other two methods without gassing becoming a problem. With further investigation and study, it was found that the cracking problem was associated more with the low-porosity spheres that were prepared. These spheres were either amorphous or had small uranium crystallite size. Therefore, it was very difficult to remove the organic reactants during the washing steps. During the drying steps, gases generated from decomposition of these contaminants caused the spheres to crack.

For use in method (3), it was found that HMTA and urea solutions could be boiled under controlled conditions and used to provide a broader range of sphere densities in a controlled manner. ${ }^{9,11}$

\subsection{Preparation of Heated HMTA-Urea Stock Solutions}

The basic heat treatment procedure involved heating a solution of 3.2 $\mathrm{M}$ HMTA and 3.2 $\mathrm{M}$ urea to the boiling point $\left(103.5^{\circ} \mathrm{C}\right)$, boiling it under reflux conditions for a predetermined time, and then quickly cooling the solution to room temperature. It was important that a good technical grade of crystalline HMTA be used. HMTA-urea solutions made with this type of HMTA are clear and remain clear when given a heat treatment. The free-flowing HMTA powder that is easy to pour should not be used because it contains detrimental additives. This type of HMTA was generally slightly discolored, and stock solutions prepared with it were also slightly discolored. When a 
solution of this type was heated, a pearlescent, oily suspension developed that would settle out upon storage. More importantly, heated stock solutions that were prepared with free-flowing HMTA did not provide favorable gel-forming behavior especially when a gel-forming temperature was $80^{\circ} \mathrm{C}$ and above.

The solubility of HMTA in water at room temperature was found to be about 3.7 M. The maximum solubility of HMTA in a solution containing 3.2 $M$ urea was only about 3.2 M. In this work, only 3.2 M HMTA solutions containing 3.2 M HMTA-urea were studied. In the preparation of heated solutions of HMTA and urea, care was given to ensure that the boiling time was the only variant. Initially, 0.5-L solutions were prepared in 1.0-L two-neck round-bottom flasks containing a thermometer and a reflux condenser. The power controller for the heating mantel was set to provide a minimum heat source, which allowed for boiling of the solutions. Heating a solution to boiling at this setting took $\sim 34$ min. On a larger scale, in which $2-\mathrm{L}$ solutions were prepared in a similar 5-L boiling glassware system, $\sim 48 \mathrm{~min}$ was required. Solutions were prepared under conditions where the boiling time was varied from 0 to $191 \mathrm{~min}$. After boiling, the solutions were quickly cooled to room temperature by placing the flask under cold running tap water. The effects of heating these solutions are discussed in next section.

\section{CHARACTERIZATION OF HEATED HMTA-UREA SOLUTIONS}

Once it was discovered that broths that were prepared with heated solutions of HMTA-urea could be used to make microspheres with lower densities and larger uranium crystallite size, an experimental effort was begun to understand and characterize this phenomenon. In the first few preparations, solutions were heated in an open beaker on a hot plate. As the solutions were boiled with stirring, there was a strong odor of ammonia $\left(\mathrm{NH}_{3}\right)$. To quantify the release of $\mathrm{NH}_{3}$ as a function of boiling time and also to minimize any loss of volume, an apparatus was set up as shown in Fig. 1. A series of traps were placed downstream from the reflux boiling flask. In the first trap, a known volume of $1.0 \mathrm{~N} \mathrm{HCl}$ was used to remove the $\mathrm{NH}_{3}$ as ammonium chloride. After each 


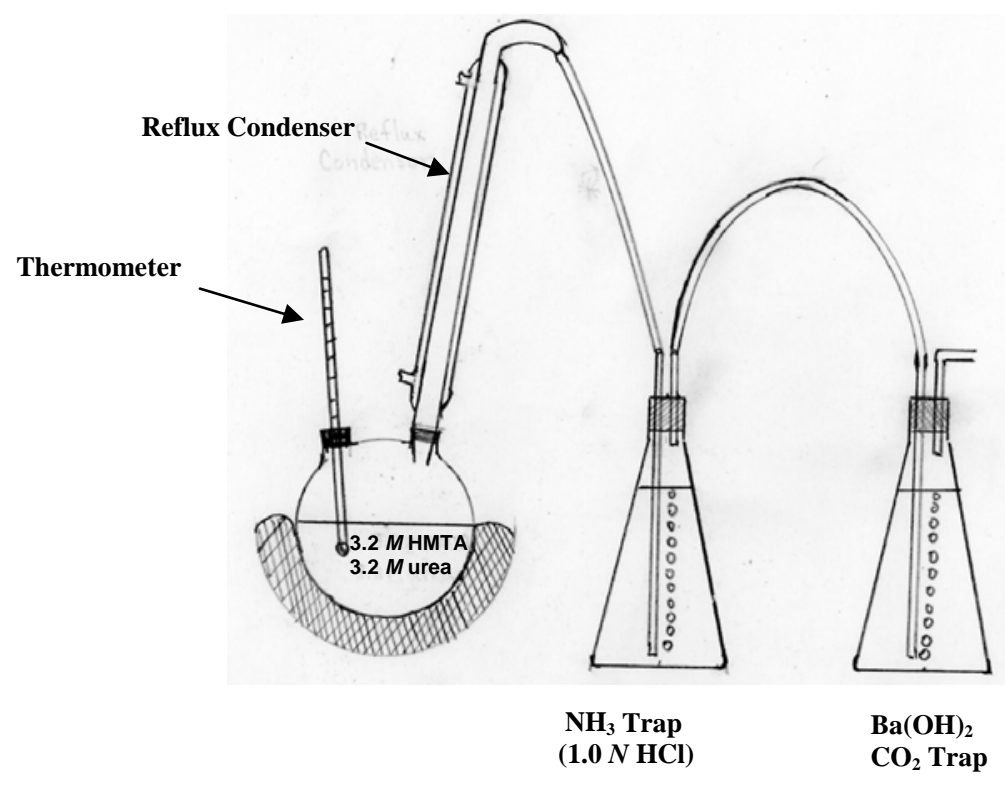

Fig. 1. Schematic of apparatus used to boil 3.2 M HMTA-3.2 $M$ urea solutions.

preparation, samples from the acid trap were potentiometrically titrated with standard $1.0 \mathrm{~N} \mathrm{NaOH}$. The amount of $\mathrm{NH}_{3}$ released from the boiling HMTA-urea was determined by the change in the acid concentration in the trap. It was discovered that the gas generated from the HMTA-urea solutions was a mixture. In the early stages of boiling, a large fraction of odorless gas passed through the acid trap. Checks of the gas exiting the apparatus with $\mathrm{pH}$ paper (wet with deionized water) showed that it contained no ammonia. In a period of $\sim 30 \mathrm{~min}$, the release of this gas slowly subsided and became insignificant. Since $\mathrm{CO}_{2}$ was a gas that could possibly be released, a second trap containing a solution of barium hydroxide was added. A whitish insoluble suspension occurs when barium hydroxide is contacted with $\mathrm{CO}_{2}$. No release of $\mathrm{CO}_{2}$ was detected in any of the preparations. It did not matter whether the trap was located upstream or downstream of the acid trap. The flame test for oxygen $\left(\mathrm{O}_{2}\right)$ also proved negative. The exit gas was directed into a thick-walled bottle filled with water and positioned upside down in a large container of water. Once the water was displaced with the gas, the bottle was removed from the larger water container. When a flaming long-stem match was inserted into the bottle, the flame quickly went out. Had the gas been $\mathrm{O}_{2}$, the flame would have glowed brightly. Although the gas could have been $\mathrm{N}_{2}$, no further effort was made to determine the identity of this gas. 


\subsection{Determination of HMTA Molarity by Potentiometric Titration}

In the course of this study over 32 aqueous solutions of HMTA and urea were prepared. Samples $(5 \mathrm{~mL})$ of these solutions were potentiometrically titrated at ice-bath temperature with standard $1.0 \mathrm{M} \mathrm{HCl}$ to determine the HMTA molarities. Urea was not found to interfere in the titrations at low temperature. Figure 2 shows examples of three different solutions (A, B, and C). Each was initially prepared at room temperature to be 3.2 $M$ in HMTA and in urea; solution A was not boiled. Solutions B and C were boiled 15 and $60 \mathrm{~min}$, respectively. Two sharp breaks were noted in each of these titration curves. The first one was for the $\mathrm{NH}_{3}$ present in the solution, and the second was for the HMTA. The volume of $1 \mathrm{M} \mathrm{HCl}$ required to reach each equivalence point is given in Fig. 2. The molarity of HMTA is determined by the difference. In each case, the HMTA molarity was 3.2, showing no change in the basicity of the HMTA. The molarities of dissolved $\mathrm{NH}_{4} \mathrm{OH}$ in $\mathrm{B}$ and $\mathrm{C}$ were 0.15 and 0.17 , respectively. Solution A, which was not heated, had only a trace amount of $\mathrm{NH}_{3}$. In each of the heated HMTA-urea preparations, a small amount of $\mathrm{NH}_{3}$ was always left in the solution. The average concentration, regardless of boiling time, was $0.15 \pm 0.03 M$. This also includes solutions that were heated just to the boiling point and subsequently quickly cooled to room temperature. It was found that the residual $\mathrm{NH}_{3}$ could be removed by stirring the solution in a covered beaker at ambient temperature for $\sim 24 \mathrm{~h}$. Titrational rechecks of stirred solutions found them to be very stable, unchanged after 1 month of storage. Although not shown in Fig. 2, a similar titration was conducted with an unheated solution that was 3.2 $M$ in HMTA and 1.7 $M$ in urea. Its titration profile was identical to the one shown for A in Fig. 2. Whether the urea was 3.2 or $1.7 \mathrm{M}$ made no apparent difference. Two $3.2 \mathrm{M}$ HMTA solutions were also prepared without adding urea. One was boiled for $60 \mathrm{~min}$, and the other was not heated. $\mathrm{No} \mathrm{NH}_{3}$ was released from the solution that was boiled. Samples of these solutions were also titrated, and both profiles were identical to trace A in Fig. 2. Considering this behavior, it appears that the release of $\mathrm{NH}_{3}$ for the boiled HMTA solutions is directly related to the presence of urea, and the release of $\mathrm{NH}_{3}$ in these solutions is probably associated with an HMTA-urea reaction. Since no release of $\mathrm{CO}_{2}$ occurred when these solutions were boiled, it appears that the formation and release 


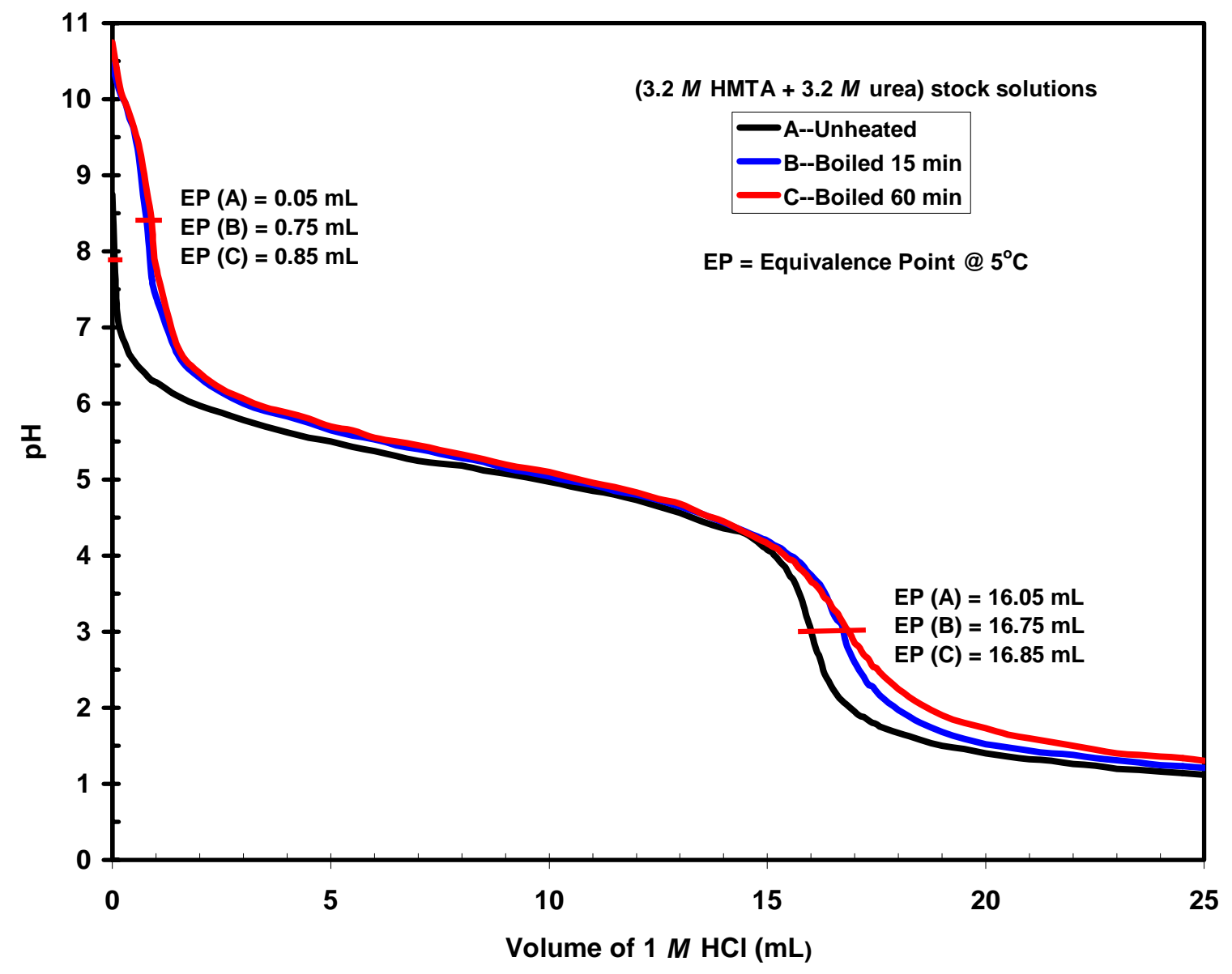

Fig. 2. Titration profiles for three HMTA-urea solutions: A, boiled for $15 \mathrm{~min}$; B, boiled for $60 \mathrm{~min}$; and $\mathrm{C}$, not boiled.

of $\mathrm{NH}_{3}$ could not just have been simply a function of urea decomposition. In a separate experiment using the apparatus in Fig. 1, a 3.2 $M$ urea solutions with no HMTA was boiled for $4.5 \mathrm{~h}$ at $100^{\circ} \mathrm{C}$. The results indicated that $3.9 \%$ of the urea was decomposed. The decomposition reaction is given by the following equation. ${ }^{18}$ Unfortunately, in this work the HMTA-urea reaction product was not identified.

$$
\left(\mathrm{NH}_{2}\right)_{2} \mathrm{CO}+\mathrm{H}_{2} \mathrm{O} \rightarrow \mathrm{CO}_{2} \uparrow+2 \mathrm{NH}_{3} \uparrow
$$

Figure 3 gives titration profiles for three HMTA-urea solutions: A was boiled for $60 \mathrm{~min}$; B, for $75 \mathrm{~min}$; and C, for $191 \mathrm{~min}$. It was found that the calculated HMTA molarities for solutions that were boiled for times $>60$ min began to decrease. These 
solutions, which are discussed in Sect. 3.3, also did not provide stable broths when boiled for more than $1 \mathrm{~h}$. A stable broth is one that does not prematurely gel before it is introduced as droplets into a heated immiscible gel-forming medium. When possible, a broth formulation is chosen that remains clear and stable at 0 to $5^{\circ} \mathrm{C}$ for $1 \mathrm{~h}$.

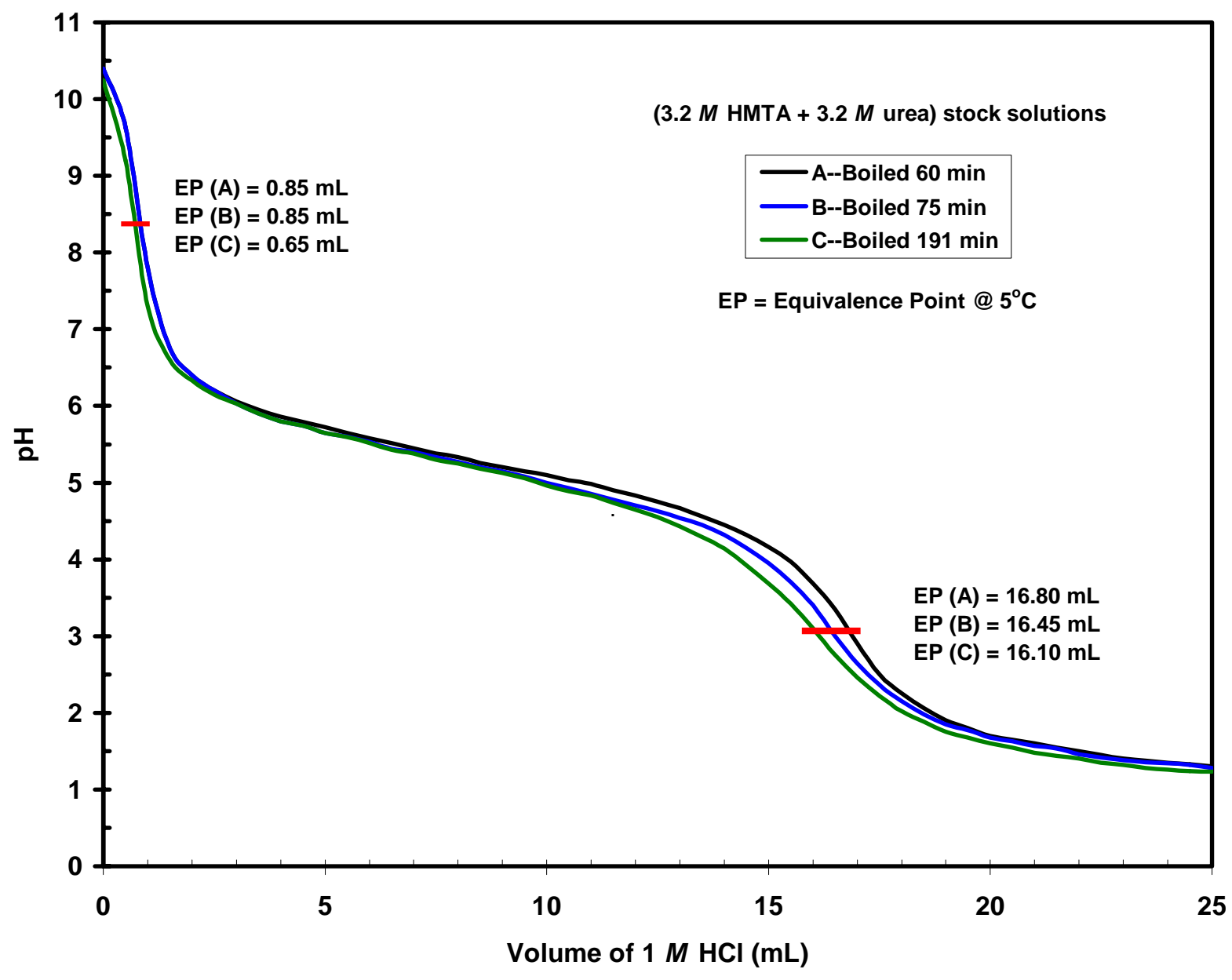

Fig. 3. Titration profiles for three HMTA-urea solutions: A, boiled for $60 \mathrm{~min}$; B, boiled for $75 \mathrm{~min}$; and C, boiled for $191 \mathrm{~min}$.

\subsection{Quantifying Ammonia Released from Heated Solutions of HMTA and Urea}

Although no change was observed in the molarity of the HMTA for boiling times of $60 \mathrm{~min}$ or less, considerable $\mathrm{NH}_{3}$ was released. The plot in Fig. 4 gives the moles of $\mathrm{NH}_{3}$ generated from boiling 0.5 - and 2-L solutions of $3.2 \mathrm{M}$ HMTA and $3.2 \mathrm{M}$ urea. 
These values represent the $\mathrm{NH}_{3}$ removed by the acid trap plus the residual $\mathrm{NH}_{3}$ in the HMTA-urea solutions. These data show that after $15 \mathrm{~min}$ of boiling, the rate of $\mathrm{NH}_{3}$ generated from the reaction is fairly constant and that 3.6 to 3.8 times more $\mathrm{NH}_{3}$ was generated in the 2-L preparations than in the 0.5 -L preparations for equal boiling times. If all the other factors were identical, the factor would have been 4 . The release of $\mathrm{NH}_{3}$ is the key to preparing stock solutions of any volumes. For example, a 4-L stock solution was prepared that yielded gel-forming properties identical to those of a 2 -L preparation that was boiled for $40 \mathrm{~min}$. The 4 -L preparation was boiled until 2 mol of $\mathrm{NH}_{3}$ was released, or twice the amount released from the 2-L preparation. The key to obtaining the desired product is to incorporate a continuous measuring device downstream that will analytically measure the $\mathrm{NH}_{3}$ released to the off gas.

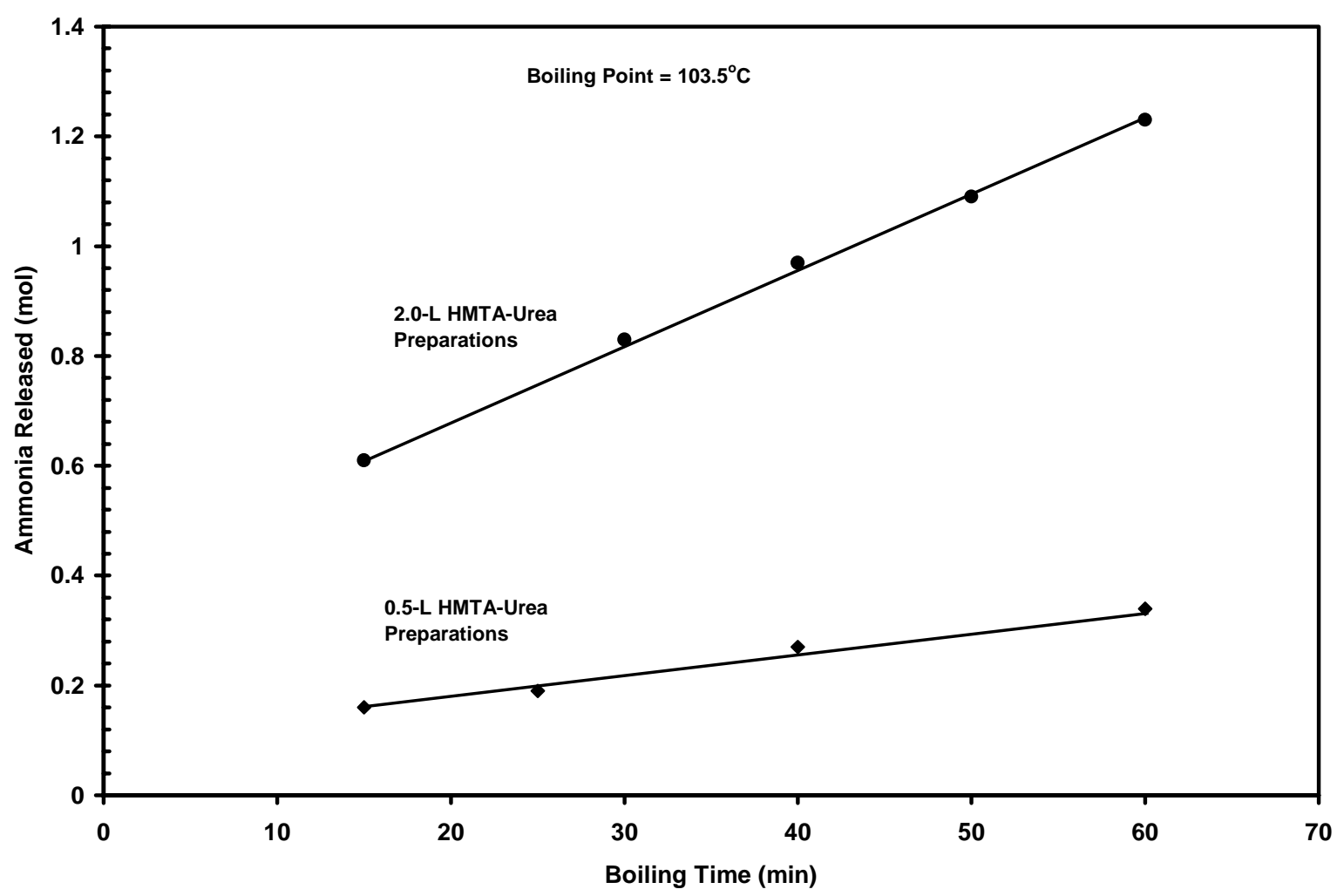

Fig. 4. Moles of $\mathrm{NH}_{3}$ released from 0.5- and 2-L solutions of 3.2 M HMTA3.2 $M$ urea as a function of boiling time. 


\subsection{Stability and Scale-up}

Two series of preparations of boiled HMTA-urea solutions were conducted to determine broth stability and the feasibility of scaleup (see Table 1). The scaleup involved going from boiling 0.5 - $\mathrm{L}$ solutions in a 1.0-L flask to boiling 2-L solutions in a 5-L flask (Fig. 1). The power controller for the heating mantel in each series was set to provide the minimum amount of heat to maintain boiling. In the internal gelation process, it is necessary that the broth does not prematurely gel when it is prepared at low temperatures $\left(0\right.$ to $\left.5^{\circ} \mathrm{C}\right)$ and that the broth remains stable (clear) for a sufficient period of time to allow for sphere-forming operations. A stable broth that does not begin to gel (to become opaque) in less than $1 \mathrm{~h}$ is considered ideal. The scale-up goal was to determine the feasibility of preparing identical solutions with the same boiling times that would have given broths with similar stabilities and produced microspheres with identical tap densities and physical properties. The method of heating that was used worked fairly well, considering the difference in solution volumes. The broth stability data in Table 1 show that all the broths were stable for $>300 \mathrm{~min}$ when boiled $50 \mathrm{~min}$ or less. For the preparations boiled for $60 \mathrm{~min}$, the 0.5 -L solutions were less stable $(25 \mathrm{~min})$ than the

Table 1. Broth stability tests ${ }^{a}$

\begin{tabular}{ccc}
\hline & \multicolumn{2}{c}{$\begin{array}{c}\text { Broth gelation time } \\
(\mathrm{min})\end{array}$} \\
\cline { 2 - 3 } $\begin{array}{c}\text { Boiling time } \\
(\mathrm{min})\end{array}$ & Solution A & Solution B \\
\hline 0 & $>300$ & $>300$ \\
15 & $>300$ & $>300$ \\
25 & $>300$ & $>300$ \\
40 & $>300$ & $>300$ \\
50 & & $200 \pm 5$ \\
60 & 25 & \\
75 & $<3 \mathrm{~s}$ & \\
191 & $<3 \mathrm{~s}$ & \\
\hline${ }^{a}$ Solutions A $(0.5 \mathrm{~L})$ and B $(2 \mathrm{~L})$ were initially $3.2 M$ in HMTA
\end{tabular}

and 3.2 $M$ in urea. Parameters for each broth: temp. $=0^{\circ} \mathrm{C} ;(\mathrm{U}+\mathrm{Pu})$ concentration $=1.11 \mathrm{M}$; percentage of plutonium in broth $=23$; $\mathrm{NO}_{3}{ }^{-} /(\mathrm{U}+\mathrm{Pu})$ mole ratio $=1.78$; and $\mathrm{HMTA} /(\mathrm{U}+\mathrm{Pu})$ mole ratio $=1.65$. 
2.0-L solutions $(200 \pm 5 \mathrm{~min})$. Successful microsphere preparations were made with all the solutions that were boiled for $60 \mathrm{~min}$ or less.

A series of gel-sphere preparations were made with a $[\mathrm{U}+\mathrm{Pu}(23.3 \%)]$ broth formulation that was found ideal for use with an unheated HMTA-urea stock. It had the following characteristics: (HMTA-urea)/(U $+\mathrm{Pu})$ and $\mathrm{NO}_{3}{ }^{-} /(\mathrm{U}+\mathrm{Pu})$ mole ratios of 1.65 and 1.82, respectively, and a $(\mathrm{U}+\mathrm{Pu})$ concentration of $1.11 \mathrm{M}$. The data in Fig. 5 indicate that the tap densities of the microspheres linearly decreased as the boiling time of the HMTA-urea solutions increased. The variance in the tap densities was more pronounced but not too significant for microspheres made with solutions that were boiled for shorter periods of time. For solutions boiled $60 \mathrm{~min}$, the tap densities were almost identical, about $0.93 \mathrm{~g} / \mathrm{cm}^{3}$. Another important observation was that the time of gelation decreased from 10.5 to $6 \mathrm{~s}$ as the boiling time HMTA-urea solution was increased to 60 min. The data in Table 1 and Fig. 5 should be very useful in determining any corrective adjustments that might be needed for scaleup.

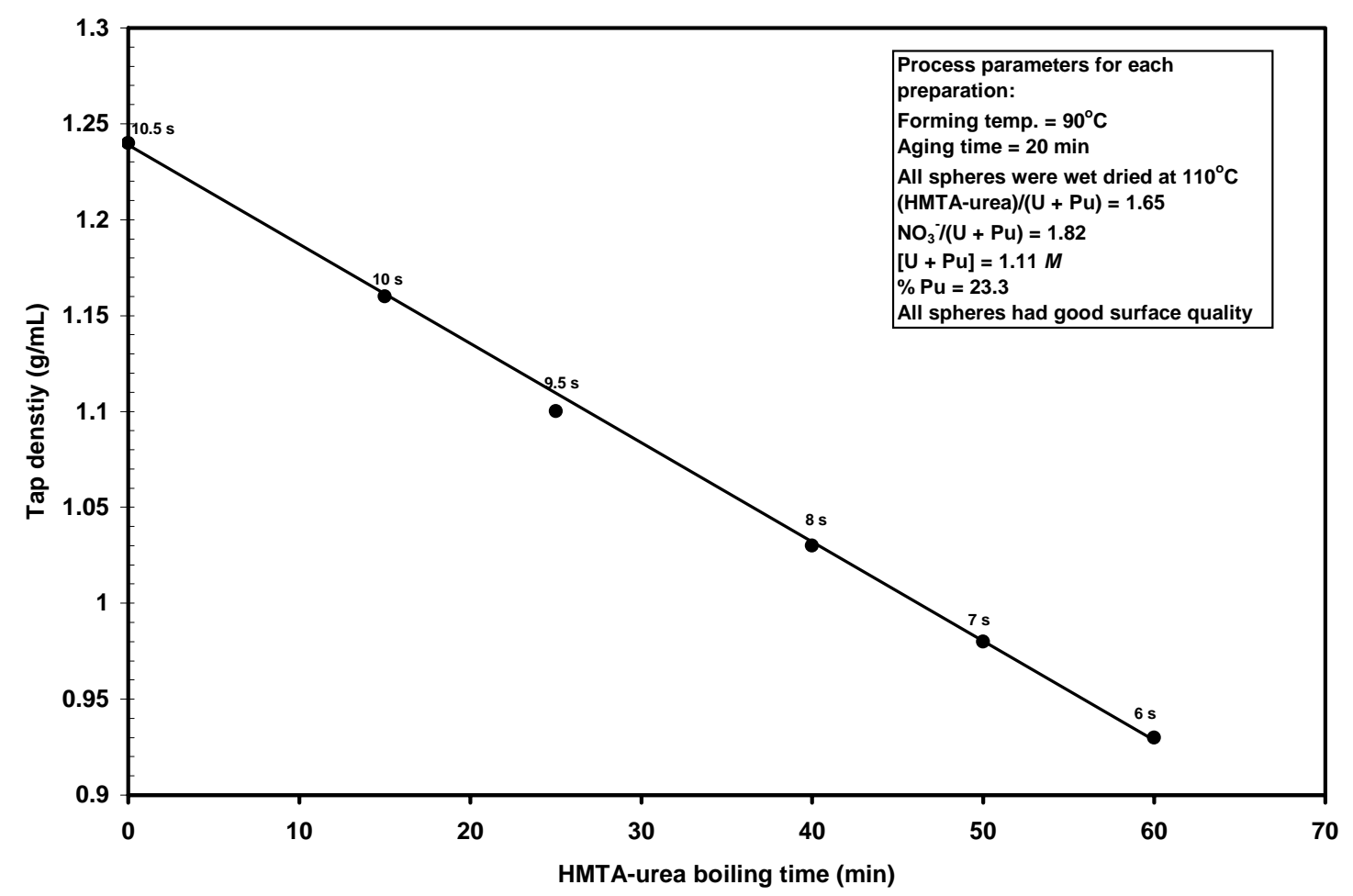

Fig. 5. Effect of HMTA-urea boiling time on tap density. 
Figure 6 shows the effect on tap density of changing the HMTA/(U + Pu) ratio for 3.2 M HMTA-3.2 $M$ urea stock solutions that were either boiled for $60 \mathrm{~min}$ or not heated. In this series of preparations, the forming temperature was $90^{\circ} \mathrm{C}$ and the aging time was 20 min. The $\mathrm{NO}_{3}{ }^{-} /(\mathrm{U}+\mathrm{Pu})$ mole ratio and $(\mathrm{U}+\mathrm{Pu})$ concentration $(23.3 \% \mathrm{Pu})$ in the broth were held constant at 1.9 and $1.11 \mathrm{M}$, respectively. The tap densities obtained using unheated HMTA-urea solution ranged from 1.23 to $1.30 \mathrm{~g} / \mathrm{cm}^{3}$. All of the preparations in Fig. 6 in which unheated HMTA-urea solutions were used yielded microspheres with good surface quality, as indicated by the small amount of surface leaching that occurred during the washing steps. For these preparations, the best-quality microspheres, which had little surface leaching, were made when the HMTA/(U + Pu) mole ratios in the broth were in the narrow range of 1.9 to 2.0 .

The effect of $\mathrm{NO}_{3}{ }^{-} /(\mathrm{U}+\mathrm{Pu})$ mole ratio on gelation time, tap density, and surface quality is shown in Fig. 7 for a series of microsphere preparations in which a 3.2 $M$ HMTA-3.2 $M$ urea stock solution was either not heated or was boiled for $60 \mathrm{~min}$.

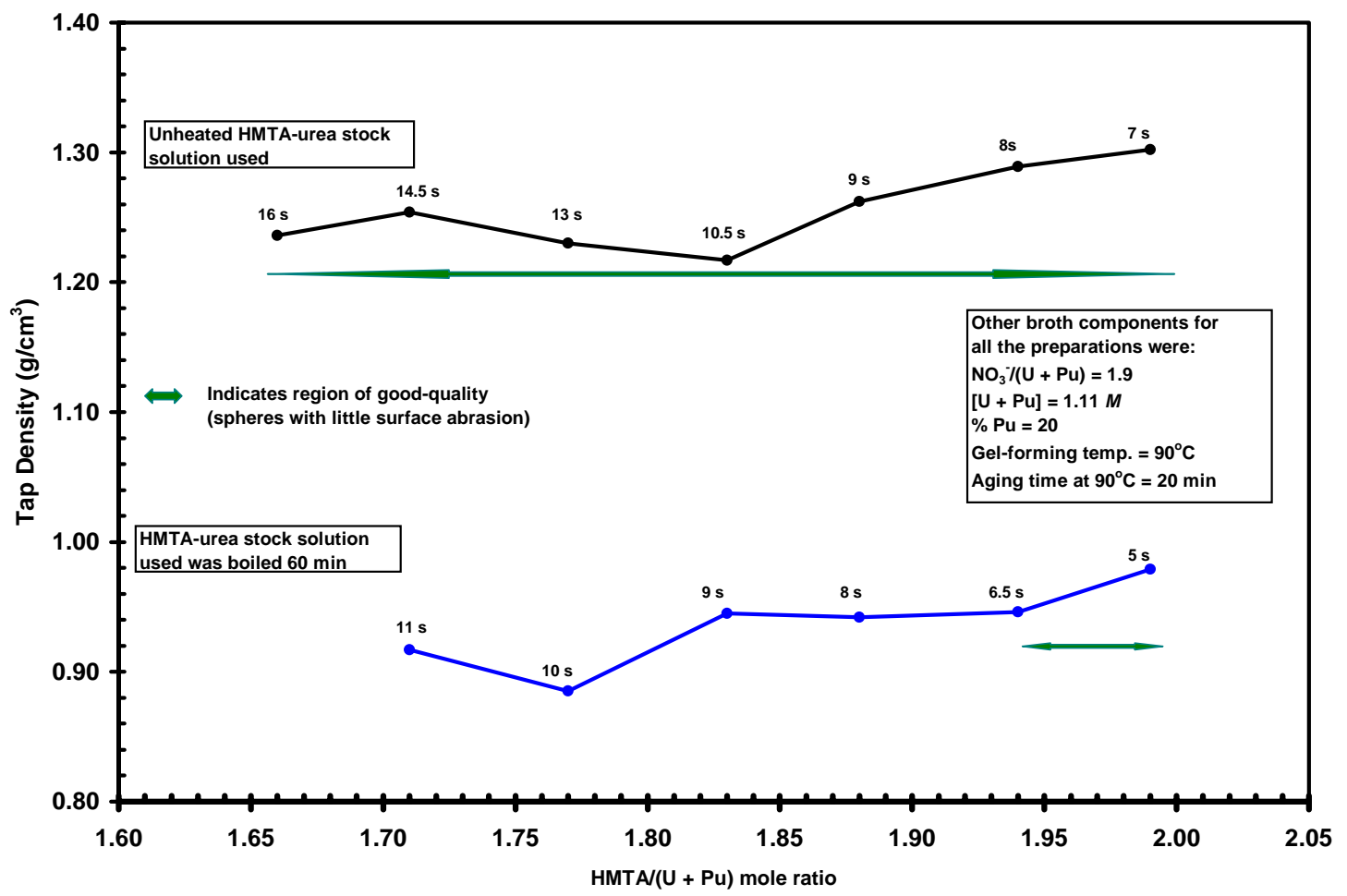

Fig. 6. Effect of changing HMTA/(U + Pu) mole ratio on gelation time, tap density, and surface quality for unheated and 60-min boiled 3.2 M HMTA-3.2 M urea solutions. 


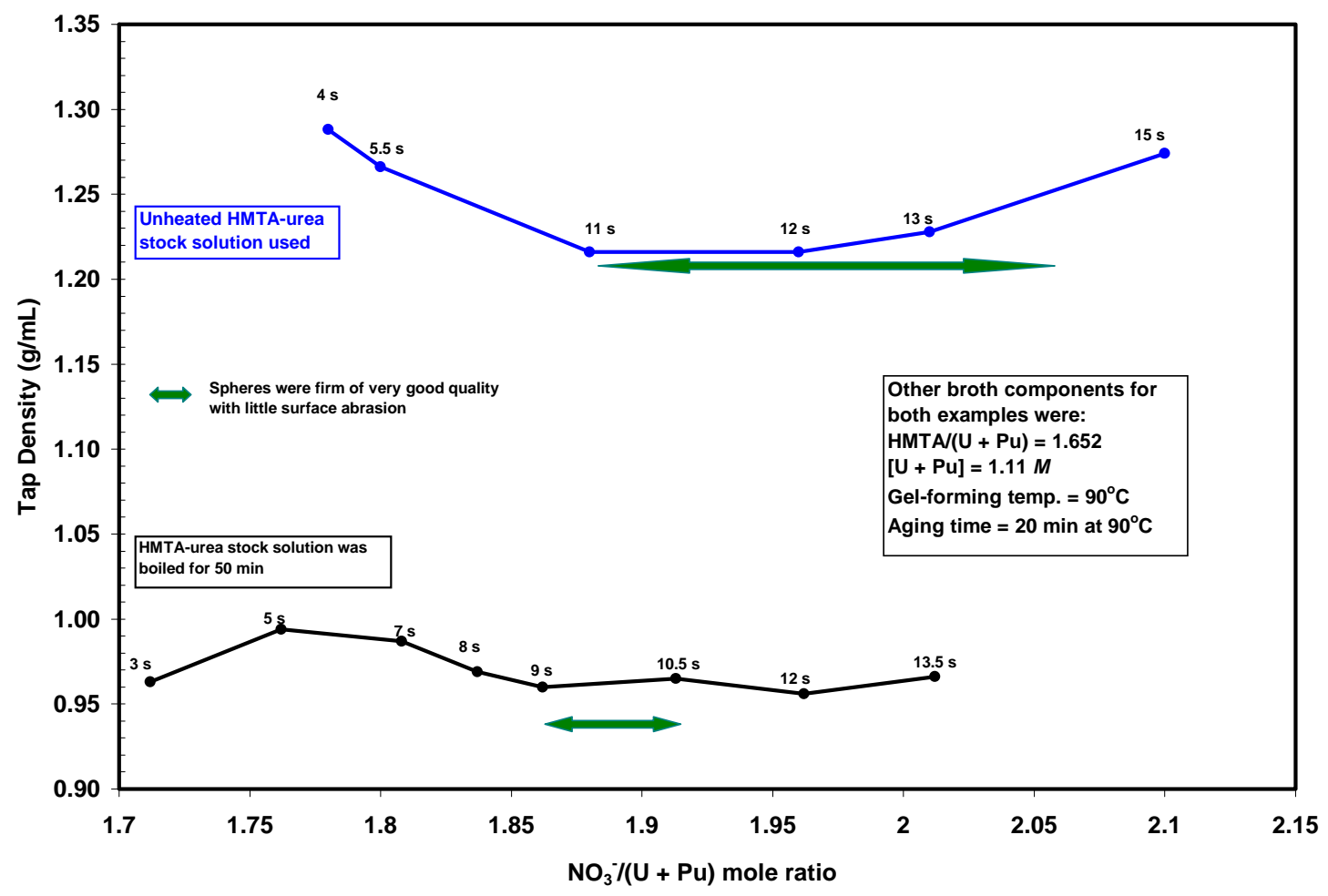

Fig. 7. Effect of varying the $\mathrm{NO}_{3}{ }^{-} /(\mathrm{U}+\mathrm{Pu})$ mole ratio on gelation time, tap density, and surface quality for unheated and 60-min boiled 3.3 M HMTA-3.2 M urea solutions.

In these preparations, $\mathrm{HMTA} /(\mathrm{U}+\mathrm{Pu})(23.3 \% \mathrm{Pu})$ with a mole ratio of 1.65 and a $(\mathrm{U}+\mathrm{Pu})$ concentration of $1.11 \mathrm{~g} / \mathrm{mL}$ were held constant. The forming temperature was $90^{\circ} \mathrm{C}$, and the aging time was $20 \mathrm{~min}$. For both of the unheated and boiled preparations, the gelation times increased as the $\mathrm{NO}_{3}^{-} /(\mathrm{U}+\mathrm{Pu})$ mole ratio was increased. The tap densities obtained using an unheated HMTA-urea solution ranged from 1.23 to $1.29 \mathrm{~g} / \mathrm{cm}^{3}$. The preparations that gave microspheres with good surface quality had $\mathrm{NO}_{3}^{-} /(\mathrm{U}+\mathrm{Pu})$ mole ratios in the range of 1.85 to 2.05 . The best $\mathrm{NO}_{3}^{-} /(\mathrm{U}+\mathrm{Pu})$ mole ratios for the boiled HMTA-urea solution was in the narrower range of 1.85 to 1.95 . The tap densities ranged from 0.96 to $0.99 \mathrm{~g} / \mathrm{cm}^{3}$.

Examination of the data in Figs. 6 and 7 reveals that a $\mathrm{NO}_{3}^{-} /(\mathrm{U}+\mathrm{Pu})$ mole ratio of $1.9 \pm 0.05$ with an $\mathrm{HMTA} /(\mathrm{U}+\mathrm{Pu})$ mole ratio ranging from 1.65 to 2 will produce good microspheres. However, the microspheres with the best surface quality had an $\mathrm{HMTA} /(\mathrm{U}+\mathrm{Pu})$ mole ratio of $\sim 1.95$. This broth also had a shorter gelation time $(6 \mathrm{~s})$, compared with $\sim 11 \mathrm{~s}$ for the broth with an $\mathrm{HMTA} /(\mathrm{U}+\mathrm{Pu})$ mole ratio of 1.65 . The 
missing variable that is needed to produce microspheres with the best surface quality is the $(\mathrm{U}+\mathrm{Pu})$ concentration of the broth. The $(\mathrm{U}+\mathrm{Pu})$ concentration in the broth was $1.11 M$. If the behavior is similar to that of the pure uranium system, increasing the $(\mathrm{U}+\mathrm{Pu})$ concentration of the broth would allow the HMTA/(U $+\mathrm{Pu})$ mole ratio of the broth to be lowered while good surface quality is maintained.

\subsection{Role of Urea in Heated HMTA-Urea Solutions}

Whether or not a broth is stable at 0 to $5^{\circ} \mathrm{C}$ depends on the urea in the broth available to complex the metal ion. When a solution HMTA-urea is boiled, the urea appears to be slowly consumed. Under the conditions used, broths from solutions that were boiled longer than 60 min were not stable. Several experiments were conducted in which additional urea was added to solutions that were boiled $60 \mathrm{~min}$ or longer to determine if stable broths with lower tap densities could be prepared. Sufficient quantities of urea were added to the "A" solutions in Table 1 that were boiled 60 and $75 \mathrm{~min}$ to increase the urea/(U+Pu) mole ratio by 0.25 and 0.55 , respectively. The gelation times for broths at 0 to $5^{\circ} \mathrm{C}$ (or the stability of these broths) were extended to $>300$ min; in other words, they became usable broths. Preparations with these broths failed to yield microspheres with lower tap density. Furthermore, microspheres that were prepared with these broths were softer and had a tendency to stick to the walls of the forming column and connecting tubing. When these microspheres were washed with $\mathrm{NH}_{4} \mathrm{OH}$, increased surface leaching and erosion were noted. No stable broths could be prepared by the addition of urea to the HMTA-urea solution that was boiled 191 min (Table 1), even when the urea addition increased the urea/(U $+\mathrm{Pu})$ ratio by 1.1 . On the other hand, stable unheated HMTA-urea solutions could be prepared that had urea/( $\mathrm{U}+\mathrm{Pu})$ mole ratios as low as 0.9 .

In an experiment with a different approach, a solution with $3.2 M$ HMTA and $5 M$ urea, rather than 3.2, was prepared. This solution was boiled $75 \mathrm{~min}$. Initially, about 5 to $10 \%$ of the HMTA did not dissolve. However, after boiling and cooling, the HMTA did dissolve. During boiling, the amount of $\mathrm{NH}_{3}$ released appeared to be greater than normal. This effort to prepare a stable broth with an HMTA-urea solution that was heated longer 
than 60 min also failed. The time of gelation for the broth at temperatures of 0 to $5^{\circ} \mathrm{C}$ was $<6 \mathrm{~min}$. (A stable broth is one that will not gel in $60 \mathrm{~min}$.)

\subsection{Effect of Urea/(U + Pu) Mole Ratio on Tap Density and Product Quality}

A series of six experiments were conducted to determine the effect of varying the urea concentration on product quality. In this series none of the HMTA-urea solutions were boiled. Table 2 gives the tap densities for spheres (dried at $110^{\circ} \mathrm{C}$ ) that were prepared with broths with urea/(U $+\mathrm{Pu})$ mole ratios from 1.6 to 0.9 . The data show little variation in the tap density. These results, in conjunction with electron micrographs of dispersed spheres, demonstrated that variation of the urea concentration in the broth under these conditions did not alter the gelation behavior of the uranium and plutonium. During the washing steps with $\mathrm{NH}_{4} \mathrm{OH}$, little surface erosion occurred. The calcined spheres did not crack and had good surface quality.

Table 2. Effect of urea concentration in the broth on tap density ${ }^{a}$

\begin{tabular}{ccc}
\hline Run no. & Urea/(U $+\mathrm{Pu})$ & $\begin{array}{c}\text { Tap density } \\
\left(\mathrm{g} / \mathrm{cm}^{3}\right)\end{array}$ \\
\hline 160 & 1.60 & 1.28 \\
163 & 1.38 & 1.30 \\
164 & 1.28 & 1.28 \\
172 & 1.18 & 1.35 \\
168 & 1.00 & 1.27 \\
169 & 0.90 & 1.27 \\
\hline
\end{tabular}

${ }^{a}$ Parameters: forming temp. $=0{ }^{\circ} \mathrm{C}$; hot-oil aging time $=20 \mathrm{~min} ;(\mathrm{U}+\mathrm{Pu})$ concentration in broth $=1.11 \mathrm{M}$; percentage of $\mathrm{Pu}$ in broth $=23 ; \mathrm{NO}_{3}{ }^{-} /(\mathrm{U}+\mathrm{Pu})$ mole ratio $=1.78$; and $\mathrm{HMTA} /(\mathrm{U}+\mathrm{Pu})$ mole ratio $=1.65$.

Urea plays two significant roles in the internal gelation process. First, it acts as a complexing agent in a broth to prevent premature gelation. Secondly, it acts as a catalyst to speed up the rate of HMTA decomposition, which causes broth droplets to gel and precipitate when heated. In aqueous solutions, urea forms complexes with uranyl ions in a 2:1 mole ratio as shown in the equation below. ${ }^{19}$

$$
2 \mathrm{CO}\left(\mathrm{NH}_{2}\right)_{2}+\mathrm{UO}_{2}{ }^{2+} \leftrightarrow \mathrm{UO}_{2}\left[\mathrm{CO}\left(\mathrm{NH}_{2}\right)_{2}\right]_{2}{ }^{2+}
$$


In this study it was found that a mole ratio of 1:1 was adequate to provide a stable broth at $0^{\circ} \mathrm{C}$ (a broth that is stable for $\geq 1 \mathrm{~h}$ at 0 to $5^{\circ} \mathrm{C}$ ). Stable broths were prepared for a mixed-metal system of uranium and plutonium $(23 \%)$ in which the mole ratio of urea/(U $+\mathrm{Pu})$ was as low as 0.9:1 when the $\mathrm{HMTA} /(\mathrm{U}+\mathrm{Pu})$ mole ratio was 1.65. Plutonium(IV) has a stronger tendency to form complexes with urea than the other actinides. Experimental results have shown that in nitric acid the primary complexes of Plutonium(IV) with urea have the compositions $\left\{\mathrm{Pu}\left(\mathrm{NO}_{3}\right)_{3}\left[\mathrm{CO}_{2}\left(\mathrm{NH}_{2}\right)_{2}\right]_{2}\right\}^{+}$and $\left\{\mathrm{Pu}\left(\mathrm{NO}_{3}\right)_{4}\left[\mathrm{CO}_{2}\left(\mathrm{NH}_{2}\right)_{2}\right]_{2}\right\}^{\circ}$ (ref. 20). These complexes have urea/Pu mole ratios of 2:1. HMTA also has a tendency to complex with uranyl ions in a 1:1 mole ratio as $\left[\mathrm{UO}_{2}\left(\mathrm{CH}_{2}\right)_{6} \mathrm{~N}_{4}\right]^{2+}$, but this complex is thought to be much weaker that the urea complex. ${ }^{19}$ The combination complexing behavior of both HMTA and urea may help account for the fact that a mole ratio of less than 2:1 will provide stable broths and that the stability is increased as the temperature is decreased.

\section{SUMMARY}

As previously discussed, the internal gelation process used is one of the sol-gel processes developed for the preparation of microspheres of nuclear fuel in which chilled clear broth droplets of ADMN, HMTA, and urea are heated to produce homogenous gelation and solidification of the droplets, which, after washing, can be dried, calcined, and sintered to produce ceramic kernels of the required density. In the development of the internal gelation process, several process parameters were determined that served as useful tools in controlling the quality of the kernels produced. Understanding the crystal morphology of uranium is essential in making $\mathrm{UO}_{2},(\mathrm{U}, \mathrm{Pu}) \mathrm{O}_{2}$, and $\left(\mathrm{UO}_{2}+\mathrm{UC}_{2}\right)$ kernels. The crystal morphology of uranium and the concomitant microsphere properties are significantly affected by (1) the HMTA/U mole ratio, (2) the $\mathrm{NO}_{3}{ }^{-} / \mathrm{U}$ mole ratio, (3) the concentration of uranium in the broth, and (4) the gel-forming temperature. It was also found that hot-oil aging and air-drying also had important impacts on crystallite growth. Controlled utilization of these parameters makes it possible with the broth formulation and gel-forming steps to control the crystal morphology in the preparation of $\mathrm{UO}_{2}$ and $\left(\mathrm{UO}_{2}+\mathrm{PuO}_{2}\right)$ kernels. Air-dried $\left(\right.$ at $\left.110^{\circ} \mathrm{C}\right)$ gel spheres of any targeted tap density can 
be prepared within a wide range of tap densities from 1.8 to $0.8 \mathrm{~g} / \mathrm{cm}^{3}$, with the uranium crystallites varying from 10 to $500 \mathrm{~nm} .{ }^{9}$ Spheres with the highest densities were either amorphous or had the smallest crystallite size. Optimization using the above-mentioned crystal growth parameters in the preparation of $(\mathrm{U}, \mathrm{Pu}) \mathrm{O}_{2}$ kernels with unheated HMTAurea solution worked only to lower the tap density of air-dried gel spheres to $\sim 1.3 \mathrm{~g} / \mathrm{cm}^{3}$, with the uranium crystallites being primarily in the 50- to $140-\mathrm{nm}$ range. These spheres could be used as materials for use in kernel preparations for TRISO-coated AGR or Sphere Pac fuels. Pellets prepared from these spheres were about $84 \%$ of theoretical density, which was considered to be the absolute minimum density for fuel pellets used in nuclear-reactor applications.

To lower the tap density further, it was fortuitously discovered that HMTA-urea stock solutions could be boiled for certain periods of time (as described in this report) and used in the broth formulation. Excellent-quality mixed-oxide $(25 \% \mathrm{Pu})$ spheres were prepared with a tap density as low as $0.93 \mathrm{~g} / \mathrm{cm}^{3}$ with uranium crystallites of about 120 to $300 \mathrm{~nm}$. These spheres were especially suited for forming gel-derived pellets of about 93 to $95 \%$ of theoretical density. Examination of the experimental results found that a $\mathrm{NO}_{3}{ }^{-} /(\mathrm{U}+\mathrm{Pu})$ mole ratio of $1.9 \pm 0.05$ with an $\mathrm{HMTA} /(\mathrm{U}+\mathrm{Pu})$ mole ratio of 1.65 to 2 will produce good microspheres. However, the microsphere with the best surface quality had an HMTA $/(\mathrm{U}+\mathrm{Pu})$ mole ratio of $\sim 1.95$. This broth also had a lower gelation time of $6 \mathrm{~s}$, compared with $\sim 11 \mathrm{~s}$ for the HMTA/(U $+\mathrm{Pu})$ broth with a mole ratio of 1.65 . The $(\mathrm{U}+\mathrm{Pu})$ concentration in the broth was $1.11 \mathrm{M}$. In this case, the 2-L HMTA-urea solution was boiled for $60 \mathrm{~min}$, with $1.23 \mathrm{~mol} \mathrm{NH}_{3}$ generated from the urea-HMTA reaction. To prepare ideal mixed-oxide AGR kernels with good surface quality and strength for use in TRISO coating, a HMTA-urea solution that yields air-dried gel spheres with a tap density of $1.10 \pm 0.05 \mathrm{~g} / \mathrm{cm}^{3}$ would probably be optimal. Under the preparation conditions used in this work, a 2-L HMTA-urea solution would be needed that is boiled for 15 to $30 \mathrm{~min}$ with 0.61 to $0.83 \mathrm{~mol}$ of $\mathrm{NH}_{3}$ being generated. The use of boiled HMTA-urea stock solution as an additional crystal growth step has provided greater process flexibility in the production of U-Pu kernels. 


\section{REFERENCES}

1. F. W. van der Brugghens, A. J. Noothout, M. E. A. Hermans, J. B. W. Kanij, and O. Votocek, "A U(VI)-Process for Microsphere Production," in Proc. Symp. Sol-Gel Processes and Reactor Fuel Cycles, Gatlinburg, Tennessee, May 4-7, 1970, CONF700502, U.S. Atomic Energy Commission, 1970.

2. M. H. Lloyd, K. Bischoff, K. Peng, H. U. Nissen, and R. Wessicken, "Crystal Habit and Phase Attribution of U(VI) Oxides in a Gelation Process," J. Inorg. Nucl. Chem. 38, 1141-47 (1976).

3. F. J. Homan, T. B. Lindemer, E. L. Long, Jr., T. N. Tiegs, and R. L. Beatty, "Stoichiometric Effect on Performance of High-Temperature Gas-Cooled Reactor Fuels from the UCO System," Nucl. Technol. 35, 428-41 (September 1977).

4. P. A. Haas, J. M. Begovich, A. D. Ryon, and S. J. Vavruska, Chemical Flowsheet for Preparing Urania Spheres by Internal Gelation, ORNL/TM-6850, Oak Ridge National Laboratory, Oak Ridge, Tenn., July 1979.

5. J. L. Botts, R. J. Raridon, and D. A. Constanzo, Density, Acidity, and Conductivity Measurements of Uranyl Nitrate/Nitric Acid Solutions, ORNL/TM-6491, Oak Ridge National Laboratory, Oak Ridge, Tenn., October 1979.

6. P. A. Haas, J. M. Begovich, A. D. Ryon, and J. S. Vavruska, "Chemical Flowsheet Conditions for Preparing Urania Spheres by Internal Gelation," Ind. Eng. Chem. Prod. Res. Dev. 19(3), 459-67 (1980).

7. R. D. Spence, V. L. Fowler, and A. D. Ryon, Equipment for Laboratory-Scale Production of $(\mathrm{U}, \mathrm{Pu}) \mathrm{O}_{2}$ Spheres by the Internal Gelation Process Using Silicone Oil, ORNL/TM-8696, Oak Ridge National Laboratory, Oak Ridge, Tenn., 1983.

8. M. H. Lloyd, "Coprocessed Nuclear Fuels Containing (U,Pu) Values as Oxides, Carbides, and Carbonitrides,” U.S. Patent No. 4,397,778, August 9, 1983.

9. M. H. Lloyd, J. L. Collins, R. L. Fellows, S. E. Shell, D. H. Newman, and W. B. Stines, A Gel Sphere Process for FBR Fuel Fabrication from Coprocessed Feed, ORNL/TM-8399, Oak Ridge National Laboratory, Oak Ridge, Tenn., February 1983.

10. J. L. Collins, M. F. Lloyd, and R. L. Fellows, Effects of Process Variables on Reaction Mechanisms Responsible for ADUN Hydrolysis, Precipitation, and Gelation in the Internal Gelation Gel-Sphere Process, ORNL/TM-8818, Oak Ridge National Laboratory, Oak Ridge, Tenn., April 1984. 
11. M. H. Lloyd, J. L. Collins, and S. E. Shell, "Method of Controlling Crystallite Size in Nuclear-Reactor Fuels,” U.S. Patent No. 4,502,987, March 5, 1985.

12. J. L. Collins, M. F. Lloyd, and R. L. Fellows, "The Basic Chemistry Involved in the Internal-Gelation Method of Precipitating Uranium as Determined by $\mathrm{pH}$ Measurements," Radiochim. Acta 42, 121-34 (1987).

13. P. A. Haas, V. L. Fowler, and M. H. Lloyd, "Preparation of Nuclear Spheres by Floatation-Internal Gelation,” U.S. Patent No. 4,663,093, May 5, 1987.

14. B. B. Spencer and M. E. Whatley, Determination of Nitric Acid and Uranium Concentrations in Aqueous Solution from Measurements of Electrical Conductivity, Density, and Temperature, ORNL/TM-11365, Oak Ridge National Laboratory, Oak Ridge, Tenn., November 1990.

15. P. A. Haas, "Formation of Uniform Liquid Drops by Application of Vibration to Laminar Jets," Ind. Eng. Chem. Res. 31(3), 359-67 (1992).

16. P. A. Haas, "A New Apparatus for Continuous Countercurrent Flow of Solids and Liquids,” Sep. Sci. Technol. 28(8), 1579-94 (1993).

17. J. L. Collins, R. D. Hunt, G. D. Del Cul, and D. F. Williams, Production of Depleted $\mathrm{UO}_{2}$ Kernels for the Advanced Gas-Cooled Reactor Program for Use in Triso Coating Development, ORNL/TM-2004/123, November 2004.

18. M. E. A. Hermans, "The Urea Process for $\mathrm{UO}_{2}$ Production," Ph.D. Thesis, Delft University of Technology, 1963.

19. J. B. Kanij, A. J. Noothout, and O. Votocek, "The KEMA U(VI)-Process for the Production of $\mathrm{UO}_{2}$ Microspheres," pp. 185-195 in Sol-Gel Processes for Fuel Fabrication, IAEA-161, International Atomic Energy Agency, Vienna, 1974.

20. V. S. Shmidt, V. S. Sokolov, and L. M. Lirillov, "Complex Formation by Quadrivalent Actinides with Urea in Nitric Acid," Russ. J. Inorg. Chem., 16(3), 418-20 (1971). 



\title{
ELECTRONIC DISTRIBUTION
}

\author{
Gary Bell, Oak Ridge National Laboratory \\ Jeff Binder, Oak Ridge National Laboratory \\ Emory Collins, Oak Ridge National Laboratory \\ Jack Collins, Oak Ridge National Laboratory \\ Guillermo Del Cul, Oak Ridge National Laboratory \\ Matt Ebner, Idaho National Laboratory \\ Charles Forsberg, Oak Ridge National Laboratory \\ Sherrell Greene, Oak Ridge National Laboratory \\ David J. Hill, Oak Ridge National Laboratory \\ Rodney Hunt, Oak Ridge National Laboratory \\ Alan Icenhour, Oak Ridge National Laboratory \\ Doug Lee, Oak Ridge National Laboratory \\ Ben Lewis, Oak Ridge National Laboratory \\ Gordon Michaels, Oak Ridge National Laboratory \\ Bob Morris, Oak Ridge National Laboratory \\ David Moses, Oak Ridge National Laboratory \\ Jim Rushton, Oak Ridge National Laboratory \\ Roger Spence, Oak Ridge National Laboratory \\ Barry Spencer, Oak Ridge National Laboratory \\ Bob Wham, Oak Ridge National Laboratory \\ David Williams, Oak Ridge National Laboratory
}

